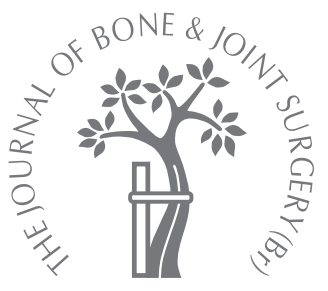

- CASE REPORT

\title{
Transient femoral nerve palsy associated with a synovial cyst of the hip in a patient with spinal cord injury
}

\author{
K. P. Robinson, \\ F. A. Carroll, \\ M. J. Bull, \\ M. McClelland, \\ I. Stockley
}

From Northern

General Hospital, Sheffield, England

- K. P. Robinson, $\mathrm{MBChB}$, BMedSci(Hons), Senior House Officer in Trauma \&

Orthopaedics

F. A. Carroll, FRCS(Tr \& Orth) Hip Fellow

I. Stockley, MD, FRCS,

Consultant Orthopaedic

Surgeon

Arthroplasty Unit

M. J. Bull, FRCR, Consultant

Radiologist

Radiology Department

M. McClelland, FRCP,

Consultant in Spinal Injuries

Spinal Injuries Unit

Northern General Hospital,

Herries Road, Sheffield S5 7AU,

UK.

Correspondence should be sent to Mr I. Stockley; e-mail: lan.Stockley@sth.nhs.uk

(c)2007 British Editorial Society of Bone and Joint Surgery doi:10.1302/0301-620X.89B1. $18273 \$ 2.00$

$J$ Bone Joint Surg $[\mathrm{Br}]$ 2007;89-B:107-8.

Received 15 June 2006;

Accepted after revision 31

August 2006

\begin{abstract}
We report a case of local compression-induced transient femoral nerve palsy in a 46-yearold man. He had previously undergone surgical release of the soft tissues anterior to both hip joints because of contractures following spinal injury. An MRI scan confirmed a synovial cyst originating from the left hip joint, lying adjacent to the femoral nerve. The cyst expanded on standing, causing a transient femoral nerve palsy. The symptoms resolved after excision of the cyst.
\end{abstract}

Synovial cysts of the hip are uncommon; ${ }^{1-4}$ they occasionally occur after trauma and may cause nerve compression. ${ }^{3,4}$ We report the case of a 46-year-old man who had bilateral hip contractures following a spinal injury. $\mathrm{He}$ underwent soft-tissue releases of both hips and developed a left-sided synovial cyst with a femoral nerve palsy which resolved following excision of the cyst.

\section{Case report}

The patient had been involved in a military aerial training accident 14 years previously, sustaining multiple injuries including a T11/12 fracture with an associated incomplete spinal cord injury, which was classified as grade D on the Frankel scale, with functional muscle power below the level of the lesion. Associated injuries necessitated a partial pulmonectomy and osteosynthesis of an ankle fracture. He had made a good recovery and remained very active, enjoying skiing. $\mathrm{He}$ is a professional pilot. He intermittently self-catheterises and is able to stand, relying more on his left leg than on his right.

In 1995 he underwent bilateral release of hip contractures. He developed a swelling over the left anterior or superior iliac spine several weeks later. It increased in size on standing and caused an electric shock sensation and numbness in the thigh. Within a few minutes there would be paralysis of the left quadriceps, which resolved when he sat down.

An MR scan confirmed the presence of a cyst arising from the hip joint (Figs 1 and 2). Ultrasound examination showed it to be very close to the femoral nerve. On standing, the cyst filled with fluid, compressing and possibly displacing the nerve. The cyst had been previously aspirated several times, up to 40 $\mathrm{ml}$ of fluid being removed. However, the fluid always re-accumulated over a period of a couple of weeks. It had also been injected with steroids.

Exploration was advised and the operation was performed with the patient in the supine position, with a sandbag under the hip. The skin incision was made using the previous scar along the iliac crest from the anterior superior iliac spine, as if performing a Smith-Petersen approach to the hip. It became apparent that the previous operation had involved a release of tensor fascia lata, rectus femoris, gluteus medius and minimus, and a partial release of gluteus maximus from the outer surface of the iliac crest. A cyst with a very thin wall, lying lateral to the anterior superior iliac spine and descending under the sartorius towards the hip joint, was identified. It was adherent to the outer wall of the iliac crest and communicated with the hip joint, which was exposed superiorly. The cyst was excised, leaving a cuff of tissue to close the joint, using Mitek anchors (Depuy Mitek, Johnson \& Johnson Ltd., Raynham, Massachusetts) for bony attachment. Histology confirmed the diagnosis of a synovial cyst.

At review, four months later, there had been no recurrence of the swelling, and the symptoms had resolved six weeks following surgery. The patient was once again able to stand for a prolonged period (up to one hour). 


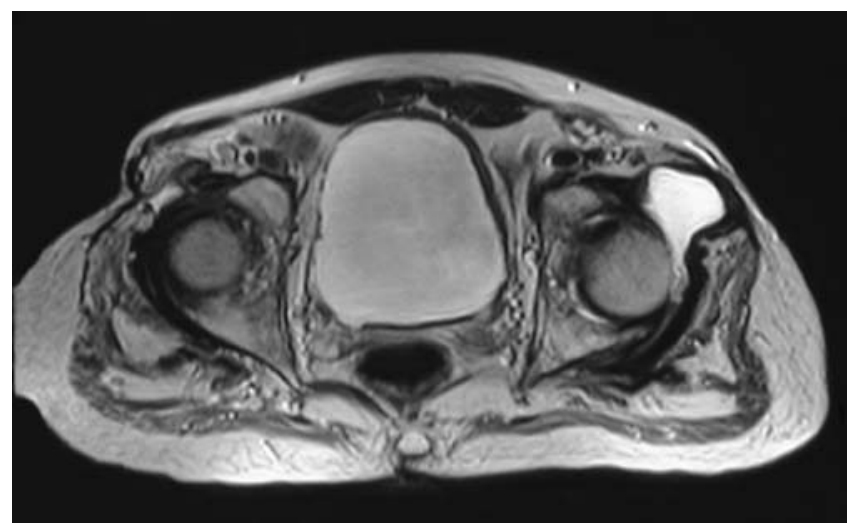

Fig. 1

Axial MR scan of the pelvis showing formation of the cyst.

\section{Discussion}

Synovial cyst formation is commonly associated with osteoarthritis, particularly in the knee and wrist. Cysts associated with the hip joint are uncommon but have been previously documented. ${ }^{1-4}$ They can cause local compression of the structures around the hip joint. Cases of femoral vessel compression ${ }^{3}$ and femoral and obturator nerve compression ${ }^{4}$ have been reported.

This is an unusual case of synovial cyst formation in the hip joint after anterior soft-tissue release, resulting in a dynamic femoral nerve palsy. Anterior soft-tissue release of the hip is a common procedure for contracture of this joint, especially in patients with cerebral palsy or following spinal cord injury. To our knowledge there are no reported cases of cyst formation communicating with the hip joint following this procedure. It is possible that, at the time of the softtissue release, the joint capsule was damaged. With his active lifestyle, it may never have had the opportunity to heal properly, and hence a cyst developed.

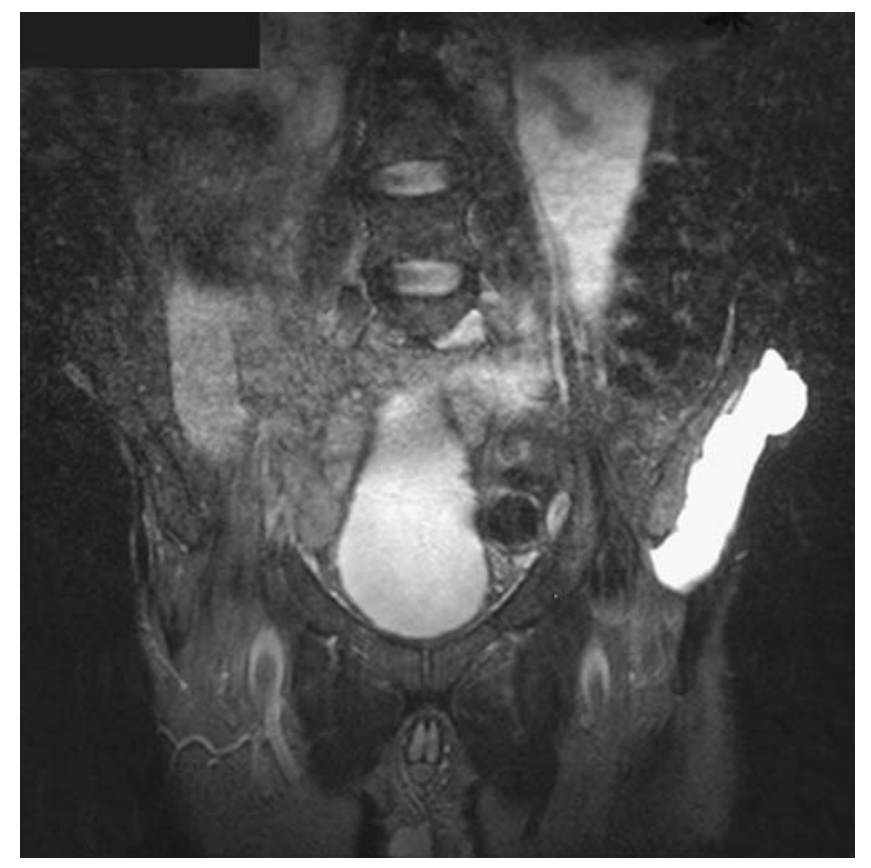

Fig. 2

Coronal MR scan of the pelvis showing its relationship to the hip joint

No benefits in any form have been received or will be received from a commercial party related directly or indirectly to the subject of this article.

\section{References}

1.White TK, Incavo SJ, Moreland MS. Giant synovial cyst of the hip joint. Orthop Rev 1988; 17:609-12.

2.Torisu T, Chosa H, Kitano M. Rheumatoid synovial cyst of the hip joint: a case report. Clin Orthop 1978;137:191-4.

3.Bystrom S, Adalberth G, Milbrink J. Giant synovial cyst of the hip: an unusual presentation with compression of the femoral vessels. Can J Surg 1995;38:368-70.

4.Stuplich M, Hottinger AF, Stoupis C, Sturzenegger M. Combined femoral and obturator neuropathy caused by synovial cyst of the hip. Muscle Nerve 2005;32:5524 